\title{
Formação docente para as práticas educativas em língua inglesa para crianças: algumas considerações
}

\author{
Teacher education for the educational practices in english language for kids: a few \\ thoughts
}

\author{
Fernanda de Mello Cardoso ${ }^{1}$. \\ Antonio Marcos da Cruz Lima ${ }^{2}$. \\ Fernanda Coelho Liberali ${ }^{3}$.
}

\section{Resumo}

Este artigo tem por objetivo refletir e problematizar a atual realidade do ensino de Língua Inglesa para crianças no Brasil. O cenário desse ensino fomenta discussões a respeito dos silenciamentos do ensino e da aprendizagem de Língua Inglesa para Anos inicias do ensino fundamental, bem como da formação de professores desta etapa do Ensino, a qual necessita de atenção especial. A metodologia utilizada é de natureza qualitativa, ancorada no método (auto)biográfico e nos estudos com narrativas. Os dados foram produzidos a partir de entrevistas realizadas com três docentes que participaram das ações formativas nos grupos colaborativos de estudos de Língua Inglesa, realizadas no programa de mestrado no contexto de pesquisas com professoras pedagogas que não obtiveram formação para lecionar Língua Inglesa enquanto graduandas da referida licenciatura. Os excertos narrativos selecionados foram aqueles que evidenciaram as fragilidades formativas das professoras que dificultam suas práticas. Os dados foram coletados por meio de narrativas contidas nas entrevistas e analisados por unidades temáticas que denominamos de eixos. Os resultados apontam que ainda há questionamentos sobre o ensino de Língua Inglesa para crianças, no que concerne à formação de professores e à elaboração de políticas públicas voltadas ao ensino de língua estrangeira. Dessa forma, interpretamos que a temática merece maior atenção e sugerimos que o trabalho colaborativo entre professores da área de Letras e da área de Pedagogia pode propiciar propostas de formação contínua que auxiliem no sentido de amenizar as angústias dos professores a respeito de sua profissionalidade sobre o ensino de Língua Inglesa para crianças, uma vez que o conhecimento formativo não se mostra suficiente para se efetivar a docência.

Palavras-chave: Língua Inglesa para crianças; Formação de Professores; Ações Formativas; Grupos Colaborativos.

\footnotetext{
Abstract

${ }^{1}$ Mestre em Educação pelo PPGEdu/UFMT. Professora da SEDUC/MT. E-mail: fernandademellocardoso@gmail.com.

${ }^{2}$ Licenciado em Letras Português/Inglês pela UFMT/Cuiabá. Mestrando em Educação do PPGEdu/UFMT.

Professor da SECITEC/MT. E-mail: thetop23@hotmail.com

${ }^{3}$ Doutora em Linguística Aplicada e Estudos da linguagem pela PUC-SP. Docente na Pontifícia Universidade

Católica de São Paulo - PUC-SP. E-mail: liberali@uol.com.br
} 
This article aims at reflecting and problematizing the existing reality of English Language teaching for kids in Brazil. The scenario has taken researchers to promote discussion regarding the silencing of the teaching and learning of English Language in the early years of basic education, and the teacher education of this stage of schooling, which regards especial attention. The methodology is of qualitative nature, anchored in the autobiographic method and the studies with narratives. The data was produced from interviews conducted with three participant teachers of the educational actions in collaborative study groups of English, developed in the master program with researches involving pedagogy teachers who did not have education to teach English Language while undergraduates in the referred licentiate. The selected narrative excerpts were those, which emphasized the teachers' educational fragilities that impair their practices. The data was collected through narratives presented in the interviews and analyzed by thematic units called axis. The results indicate that there still are questions about teaching of English Language for kids, concerning the teacher education and the formulation of public policies aimed at the teaching of foreign language. Therefore, we interpret that the theme deserves more attention and we suggest that collaborative work between teachers from both the Language and Pedagogy field can provide continuing teacher education proposals which help in the sense of mitigating the anguish from the teachers to their professionalism about teaching of English Language for kids, since their educational knowledge is not enough to consolidate teaching.

Keywords: English Language for kids; Teacher Education; Educational Actions; Collaborative Groups.

\section{Introdução}

O presente estudo propõe uma reflexão acerca da realidade do ensino de Língua Inglesa para crianças (LIC) no Brasil, subsidiada pelas discussões em duas pesquisas de mestrado que investigaram a realidade de professoras pedagogas que atuam no ensino de LIC. As investigações foram desenvolvidas na perspectiva de grupos colaborativos, em que professores licenciados em Letras Língua Inglesa ofertaram uma formação linguística para as referidas professoras com o intuito de trabalhar suas necessidades formativas no que concerne ao conhecimento de LI para práticas educativas com crianças.

No contexto do projeto colaborativo Observatório da Educação (OBEDUC), desenvolvido por meio da parceria universidade-escola, em um município do estado de Mato Grosso, constatou-se a inclusão de LIC nos anos iniciais do Ensino Fundamental (EF), na matriz curricular (RONDONÓPOLIS, 2006) sendo recomendada no primeiro ciclo $\left(1^{\circ}, 2^{\circ}\right.$ e $3^{\circ}$ ano) e obrigatória no segundo ( $4^{\circ}$ e $5^{\circ}$ ano). Diante disso, aos coordenadores do projeto colaborativo, foi solicitada uma formação específica para o trabalho de ensino de LIC, de modo a oferecer conhecimento para atender as necessidades formativas das 
professoras pedagogas, as quais afirmaram não terem recebido instrução para este tipo e prática nos estudos da graduação.

No contexto das pesquisas de mestrado, e nas atividades do grupo colaborativo, desenvolveram-se dois cursos de formação continuada com estudos para o ensino de LIC: o primeiro com carga horária de 20 horas, e o segundo com 80 horas. Os conteúdos estudados nos encontros formativos foram escolhidos de acordo com a matriz curricular do município, e, para registro, optou-se por narrativas colhidas em entrevistas e de diário de campo. As discussões entre os participantes do curso suscitaram reflexões a respeito das realidades de cada docente, suas práticas educativas e necessidades formativas para trabalhar com LIC. Os dados obtidos com as investigações revelaram que as partícipes buscam conhecimento em suas experiências enquanto discentes na Educação Básica, a partir do auxílio de colegas de trabalhos e filhos, livros didáticos e apostilas de suas próprias buscas, visto que tais materiais não são disponibilizados pela escola.

No Brasil, o ensino das diferentes áreas do conhecimento é definido e regularizado pela Lei de Diretrizes e Bases da Educação Nacional - LDBEN (BRASIL, 2006). Esse documento rege que o ensino de uma Língua Estrangeira (LE), sendo sugerida a LI, seja inserido a partir do $6^{\circ}$ ano do EF como disciplina obrigatória. Além da LDBEN (BRASIL, 2006), a DCN (BRASIL, 2013) estipula que, nos componentes curriculares obrigatórios do $\mathrm{EF}$, haja o ensino da "língua estrangeira moderna" (conforme os documentos). No entanto, observa-se, em diferentes contextos educativos, o ensino da língua sendo incluso no currículo como atividade diversificada e/ou obrigatória, nos anos iniciais do EF e, ainda, em algumas instâncias, os estudos iniciam quando bebê na Educação Infantil.

Pesquisadores como Paiva (2003), Rocha, Tonelli e Silva (2010), entre outros, apontam o aumento da busca pelo conhecimento de uma língua estrangeira no Brasil. Conforme Rocha e Liberali (2017, p. 127), "parece ser consenso a importância de aprendermos línguas estrangeiras, com vistas a uma participação social mais ampla e potencialmente mais crítica", posto que elas são "artefatos culturais que desempenham um papel crucial na educação das pessoas no mundo de hoje" (p.127). Por isso, em referência a esse fenômeno e em consonância com as discussões dos teóricos que subsidiaram o presente estudo, as autoras explicam que "o ensino de línguas nos anos iniciais favorece o contato com a diversidade, desperta o interesse sobre diferentes povos e culturas e possibilita a expansão do repertório linguístico e cultural”.

Revista Devir Educação, Lavras, vol.3, n.2, p.92-113 jul./dez., 2019. 
É fato que o conhecimento de uma língua estrangeira agrega status de poder ao falante, além de propiciar interações com outras culturas. Esse movimento favorece as relações interpessoais no contexto do mundo globalizado, não somente aos adultos, mas permeia os contextos da infância, em que crianças interatuam com as línguas, principalmente a LI, nos espaços digitais diversificados.

As prerrogativas favoráveis ao domínio de uma segunda língua explicam o ensino de LIC nas instâncias do EF antes do $6^{\circ}$ ano, por acreditar que, por essa antecipação, a criança terá a oportunidade de relacionar-se com a LI de forma didática, uma vez que ela é parte do seu cotidiano.

A antecipação do ensino de LI para crianças antes do período definido como obrigatório se explica, todavia, surgem algumas inquietações: em que espaços escolares isso acontece e como se desenvolvem tais práticas? Constata-se a inclusão do ensino, principalmente da LI, em escolas particulares e, em determinados casos, em escolas públicas municipais e/ou estaduais, caso retratado em uma das duas dissertações que embasaram esta discussão, ou seja, uma concluída e socializada, e a outra em andamento, cujo objeto de estudo foi a realidade de professoras que trabalhavam com o ensino de LIC dos anos iniciais em escolas municipais de uma cidade no estado de Mato Grosso.

Diversos outros exemplos de implantação do ensino de LI no currículo dos anos iniciais são encontrados por todo o Brasil, narrados e analisados em coletâneas científicas que apresentam mapeamentos de pesquisas desenvolvidas na área do ensino e da formação de professores para as práticas de Língua Estrangeira para Crianças (LEC). Sabe-se que as produções científicas sobre esse objeto de estudo são diversas, então, para esta reflexão nos baseamos em duas coletâneas, quais sejam Língua Estrangeira para crianças: Ensinoaprendizagem e Formação Docente de Rocha, Tonelli e Silva (2010), e Ensino e Formação de Professores de Línguas Estrangeiras para Crianças de Tonelli, Pádua e Oliveira (2017). Nesse texto, serão apresentadas algumas considerações registradas em investigações na área de ensino de LEC que foram destacadas nos trabalhos de pesquisadores ao redor do Brasil, bem como reflexões que surgiram em publicações de própria autoria.

A obra de Rocha, Tonelli e Silva (2010) problematiza o ensino e aprendizagem de LEC, a forma como é percebida pela sociedade e levanta questões referentes às políticas públicas no que tange à inserção dela nos anos iniciais. Discute ainda, a temática voltada às necessidades formativas de professores que exercem sua profissão como docentes de LI.

Revista Devir Educação, Lavras, vol.3, n.2, p.92-113 jul./dez., 2019. 
Inquietações como as apresentadas na referida obra devem ser discutidas e implementadas pelas políticas públicas que regem o ensino e a aprendizagem de LE, no caso da presente pesquisa, a LI, visto que, houve um aumento significativo na inserção da disciplina nos currículos dos anos iniciais, conforme analisam Rocha, Tonelli e Silva (2010), Tonelli, Pádua e Oliveira (2017), Rocha e Liberali (2017), Cardoso (2018), entre outros.

Em relação às necessidades formativas de professores enquanto docentes de LI, na coletânea de Rocha, Tonelli e Silva (2010), uma das problematizações abordadas é o fato da LI não fazer parte dos currículos formativos dos Cursos de Pedagogia e, tampouco, do currículo dos Cursos de Letras Inglês ou Letras Português/Inglês são apresentadas discussões sobre o ensino de LI nos anos iniciais. Assim, os autores denotam silenciamentos formativos como parte deste cenário. Esse fato torna preocupante a realidade do ensino da língua em nosso país, visto que, conforme Lima e Margori (2010, p. 190), “os estilos pedagógicos e o nível de proficiência dos professores influem no processo de aprendizagem das crianças", motivo que justifica a necessidade da realização de investigações no campo de estudo das práticas de ensino de LIC e da formação para os professores.

A obra de Tonelli, Pádua e Oliveira (2017) aponta um outro aspecto no panorama de ensino de LE no Brasil. As secretarias de educação dos municípios são orientadas pelos Parâmetros Curriculares Nacionais de Língua Estrangeira (PCN) (1998) e as Diretrizes Curriculares Nacionais (2013), as quais trazem em suas propostas, orientações sobre a introdução de línguas estrangeiras a partir do $6^{\circ}$ ano do EF. A Base Nacional Comum Curricular (BNCC) (BRASIL,2017) rege que as práticas de linguagens nos anos finais do EF somam àquelas internalizadas nos anos iniciais.

Em consonância com Rocha, Tonelli e Silva (2010), as autoras Tonelli, Pádua e Oliveira (2017) problematizam a falta de políticas que legitimam a inclusão do ensino de LEC, visto que se observa a inserção da LE nos anos iniciais há certo tempo, principalmente nas escolas privadas. O silenciamento de políticas públicas para LEC assemelha-se à característica de exclusão social para os anos iniciais do ensino público, quando estes, ao deixarem de ter acesso a uma outra língua, abstraem-se da possibilidade de aprimorar sua alteridade cidadã, aprendendo de si mesmos e do outro pelo viés da cultura e do mundo plural que os permeiam.

Revista Devir Educação, Lavras, vol.3, n.2, p.92-113 jul./dez., 2019. 
Pelo viés da cidadania, as autoras acreditam também que o ensino de LE precisa ser visto na perspectiva formadora do sujeito, alinhando-se, dessa forma, à visão de que os PCN se propõem a respeito da formação cidadã quando asseveram que "o exercício da cidadania exige o acesso de todos à totalidade dos recursos culturais relevantes para a intervenção e a participação responsável na vida social” (BRASIL, 1998, p. 27).

Outro questionamento torna-se relevante para a problematização aqui proposta: Quem são os profissionais da educação que atuam no ensino de LI para crianças?

É esperado que o profissional que lecione LI deva ter conhecimento linguístico para sua atuação, e como salientado por Richards (2008), este professor deve carregar consigo características peculiares como objetivos, valores, discurso e práticas em comum, bem como ser autocrítico de seu fazer pedagógico. No entanto, esse vislumbre não é o que expressa a realidade em muitas localidades brasileiras, visto que os contextos educacionais são múltiplos e díspares, nos quais, possivelmente, se apresentam professores ou sem capacitação linguística para desenvolver sua profissionalidade, ou sem capacitação pedagógica para tal. Esse fato desmonta o conceito esperado e "idealizado" do professor de LI.

O que acontece, em certos casos, conforme Rocha, Tonelli e Silva (2010), Tonelli, Pádua e Oliveira (2017) e Cardoso (2018), é que o ensino-aprendizagem de LI se torna responsabilidade do docente que trabalha com os anos iniciais, o profissional da unidocência. Essa responsabilidade gera uma angústia na vida do professor que não teve formação voltada para esta prática durante os estudos da graduação.

No contexto da formação inicial, percebemos o quanto os cursos de licenciatura em Pedagogia, (GATTI, 2014) e Letras Inglês (CELANI, 2010), precisam repensar a formação para os futuros docentes, de modo a suprir as necessidades formativas voltadas aos âmbitos pedagógicos e linguísticos, evitando, dessa forma, os desgastes no processo de aprendizagem do estudante de LI, levando-o a construir um conceito negativo de aprender uma nova língua.

O sentimento de incapacidade do professor dentre outras sensações, surge como elemento de estudos de autores como Nóvoa (1992), Imbernón (2009), Gatti (2014), que, muitas vezes, e em diversos contextos, apresenta em sua atuação, quadros de insegurança, insatisfações, assim como a sensação de incompetência profissional, levando esse docente a pensar em desistir da profissão, segundo Silva (2018). Para ratificar essa premissa, 
recorremos a Freire (1997, p. 103), quando este argumenta que "a incompetência profissional desqualifica a autoridade do professor".

Portanto, o presente trabalho tem como objetivo refletir e problematizar a atual realidade do ensino de LIC no Brasil, uma vez que as pesquisas evidenciam discussões a respeito de um olhar mais incisivo para os silenciamentos tanto nos currículos, quanto nas políticas públicas educacionais em relação ao ensino e aprendizagem de LI, bem como na formação de pedagogos, a qual necessita de uma atenção especial. Além disso, tem como objetivo específico investigar e analisar as fragilidades e necessidades formativas de três professoras pedagogas que exercem a profissão como docentes de LIC sem a devida formação profissional para suas práticas.

Trata-se de uma pesquisa cujo objeto de investigação define a natureza qualitativa, conforme Bogdan e Biklen (1994) e Ghedin e Franco (2011), ancorada no método (auto)biográfico e nos estudos com narrativas centrados em Cunha (1997), Nóvoa e Finger (2011), Ferrarotti (2010, 2014), Delory-Momberger (2014). Sendo assim, para a análise dos dados serão interpretados alguns trechos das entrevistas realizadas com três docentes que participaram das ações formativas nos grupos colaborativos de estudos de LI que foram realizadas nas pesquisas de mestrado. Esses grupos foram analisados com base nas leituras e estudos que nortearam a investigação, tendo em vista as necessidades formativas de professores que trabalham com a LIC.

Posto isso, as seguintes seções apresentam os fundamentos que embasaram a presente reflexão no que concerne a base teórica e a metodologia, além da análise dos dados e as considerações da discussão proposta.

\section{Fundamentação}

A fundamentação teórica se sustenta pelos estudos de duas coletâneas mencionadas na introdução deste texto: Língua Estrangeira para crianças: Ensino-aprendizagem e Formação Docente de Rocha, Tonelli e Silva (2010), e Ensino e Formação de Professores de Línguas Estrangeiras para Crianças de Tonelli, Pádua e Oliveira (2017). Nesse texto, serão apresentados alguns registros de investigações na área de ensino de LEC destacados nos trabalhos de investigadores no Brasil, bem como reflexões que surgiram em publicações de autoria desses pesquisadores.

Revista Devir Educação, Lavras, vol.3, n.2, p.92-113 jul./dez., 2019. 
É fato que, conforme apontam os autores das duas coletâneas e tantos outros estudiosos desse campo científico, aumentou a quantidade de crianças engajadas nos estudos de uma língua estrangeira nos últimos anos em nosso país (ROCHA; TONELLI; SILVA, 2010; TONELLI, PÁDUA; OLIVEIRA, 2017; ROCHA; LIBERALI, 2017; CARDOSO, 2018). Os dados evidenciados nos relatos de tais pesquisas problematizam, dentre muitos aspectos, os motivos, as instâncias, as práticas do ensino de LEC, as visões dos agentes envolvidos, professores e alunos.

No que concernem as razões para a inserção da LE no processo de ensino e aprendizagem para crianças, Szundy (2017, p. 11) no prefácio da obra de Tonelli, Pádua e Oliveira (2017), explica que, com base nos PCN (BRASIL,1998) e DCN (2006), o contato com uma língua que não a materna "pode contribuir para o/a aluno/a ampliar sua percepção de outrem, do mundo e de si mesmo". Tal afirmação torna-se crucial, principalmente no mundo atual, no qual as barreiras geográficas são atravessadas pela esfera digital em que interagem adultos e crianças desde bebês. Assim, no que diz respeito ao ensino para crianças, Rocha e Liberali (2017, p. 129) afirmam que “a aprendizagem de línguas na infância auxilia o crescimento intelectual, físico, emocional e sociocultural da criança".

Rajagopalan (2010), autor do prefácio da obra de Rocha, Tonelli e Silva (2010), levanta questionamentos cruciais para a atual discussão.

'A língua estrangeira para crianças' - este tema costuma despertar as
atenções dos pais como também dos pedagogos no mundo inteiro. Será
que expor as nossas crianças a uma língua estrangeira tão cedo no seu
período formativo é bom para elas? Ou será que, ao contrário, atrapalha
seu crescimento, redundando-se em enormes dificuldades na
aprendizagem da sua própria língua materna, confundindo suas mentes
tenras? É possível que as crianças que crescem em ambientes multilíngues
sofram para o resto de suas vidas algum dano irreparável de ordem
linguística ou cognitiva? As perguntas são das mais variadas. Assim como
também são das mais variadas as opiniões dos experts a respeito.
(RAJAGOPALAN, 2010, p. 9, grifo do autor).

Diante de tantas indagações, torna-se relevante o estudo sobre a atual realidade brasileira com relação às práticas de ensino de LI para crianças, visto que ainda há muito a ser estudado, discutido e articulado sobre este campo de atuação educativa com as crianças que ganham importância e, cada vez mais, espaço na sociedade.

Revista Devir Educação, Lavras, vol.3, n.2, p.92-113 jul./dez., 2019. 
Embora a inserção no mundo estrangeiro esteja cada vez mais frequente e abrangente, de acordo com Szundy (2017, p. 11), “o acesso à mobilidade dentre práticas de letramento em outras línguas no Brasil continua limitado às crianças de famílias mais abastadas". Do mesmo modo, Rocha, Tonelli e Silva (2010, p. 9) apoiam que é preciso superar o caráter excludente existente em práticas de ensino de LI "com vistas à superação de sua natureza autoritária, sustentada por discursos globalizantes e centralizadores", uma vez que

[...] é preciso que o inglês subverta seu papel, para que possa passar a servir como recurso para o desenvolvimento de capacidades que nos possibilitem enfrentar os novos desafios da atualidade, de forma ética e protagonista [...] (ROCHA; TONELLI; SILVA, 2010, p. 9).

Para o regimento do ensino e aprendizagem de LE na LDBEN (BRASIL,2006) e DCN (2013), como argumentado pelos autores das duas coletâneas, Paiva (2003), Rocha e Liberali (2017) e Szundy (2017, p. 12), a discussão torna-se mais significativa ainda, pois, ao declarar que a inclusão dos ensinamentos da LE seja a partir do $6^{\circ}$ ano do EF, "a própria legislação brasileira vem contribuindo para legitimar diferenças entre o ensino público e privado e, portanto, processos de exclusão social". Essa é outra razão que justifica a importância da presente reflexão e da necessidade de olharmos com maior delicadeza para as crianças envolvidas nesse processo educativo, posto que se torna injusto, caracterizando uma forma de segregação social quando uns têm a oportunidade de estudo e outros não.

Outro ponto preocupante, mencionado na introdução deste artigo, é o professor que atua com essas crianças. Ao professor formado em Letras é oferecida uma formação inicial que tem como base os documentos curriculares nacionais da Educação Básica, por isso abordam a formação desse profissional segundo o que rege a LDBEN (BRASIL, 2006). O professor formado em Pedagogia, o qual atua com as crianças desde a Educação Infantil até os anos iniciais do EF, não tem no currículo do seu curso, na grande maioria, o ensino de alguma LE. Assim, surgem algumas indagações: 1) quem deve atuar no ensino e aprendizagem de LEC, o professor formado em Letras ou o professor formado em Pedagogia? 2) quais políticas estão sendo elaboradas para legitimar o trabalho do ensino e aprendizagem de LEC?

Revista Devir Educação, Lavras, vol.3, n.2, p.92-113 jul./dez., 2019. 
Pelas questões levantadas, torna-se significativo "problematizar de forma mais efetiva as práticas e políticas (ou falta de) voltadas para o ensino-aprendizagem de línguas adicionais na infância e formação inicial e continuada de professores para esse público" (SZUNDY, 2017, p. 12).

A despeito da formação de professores e da profissão docente, Novóa (1992), Imbernón (2009), Gatti (2014), André (2016) e Tardif (2017) afirmam a necessidade de dotar os professores de saberes provenientes de uma formação contínua que os permita refletir sobre a prática, vislumbrar outras ações e, dessa forma, buscar consolidar sua autonomia profissional. Tal engajamento dos estudos da profissão pode auxiliar o professor no sentido de amenizar as angústias da profissão, causadas por inúmeros fatores, inclusive a falta de formação sobre determinada disciplina.

De acordo com Cunha (1997) e Nóvoa e Finger (2010), o uso de narrativas no trabalho formativo com pessoas se faz pertinente, posto que elas trazem luz às trajetórias de vida e historicidade vivenciadas, bem como na profissão docente, o foco dessa pesquisa.

Tendo em vista os estudos sobre grupos colaborativos (ANDRÉ, 2016; PASSOS, 2016), sugerimos que uma forma de contribuir para amenizar as angústias da profissão dos professores que atuam com o ensino de LIC sem ter o conhecimento formativo para tanto, é a partir de ações de formação contínua que se desenvolvem com a parceria de professores formados em Letras e Pedagogia e pesquisadores que almejam um mesmo objetivo, isto é, realizar um processo de ensino e aprendizagem adequado para o público alvo em questão.

Vislumbramos a possibilidade da troca de aprendizagem em instâncias de grupos colaborativos e reflexivos, visto que, de acordo com Passos (2016), estes são

[...] como espaços formativos que qualificam a trajetória profissional dos professores e que permitem colocá-los em constante aprendizagem docente decorrente do desenvolvimento da reflexão e da crítica sobre si mesmos e sobre suas práticas [...] (PASSOS, 2016, p. 165).

Os apontamentos nesse texto contribuem para refletirmos sobre a atual realidade do ensino e aprendizagem de LEC, posto que as pesquisas evidenciam que existe a prática de inserção do estudo das línguas, principalmente a LI, nos anos inicias, portanto, há a necessidade de discutirmos o que vem sendo construído, para cogitarmos o que pode ser articulado para que práticas sejam aprimoradas e mais crianças sejam assistidas.

Revista Devir Educação, Lavras, vol.3, n.2, p.92-113 jul./dez., 2019. 


\section{Metodologia}

A abordagem da investigação é qualitativa e está ancorada no método (auto)biográfico e nos estudos com narrativas (CUNHA, 1997; DELORY-MOMBERGER, 2014; FERRAROTTI, 2010, 2014; FINGER, 2010; NÓVOA, 1992).

A pesquisa qualitativa tem como parâmetro principal a investigação de fenômenos em relação à natureza e aos contextos em que eles se desenvolvem (AGRA; IFA, 2017), e este estudo se alinha à essa abordagem devido à sua preocupação eminentemente social.

Ao entendermos que a abordagem qualitativa se respalda nos processos de compreensão e interpretação do que é observado e coletado, nos ancoramos na afirmação de Ghedin e Franco (2011) quando estes sugerem que

[...] a pesquisa qualitativa vai permitir a compreensão do cotidiano como possibilidade de vivências únicas, impregnadas de sentido, realçando a esfera do intersubjetivo, da interação, da comunicação, e proclamando-o como espaço onde as mudanças podem ser pressentidas e anunciadas. (GHEDIN; FRANCO, 2011, p. 61).

Um outro fator de merecido destaque neste tipo de metodologia é que os dados coletados são predominantemente descritivos, bem como a presença de um olhar cuidadoso pelo processo em si, em detrimento do produto, como afirmam Lüdke e André (1986).

Os dados de pesquisa foram levantados por meio de narrativas, pela compreensão de que elas estimulam a reflexão e tomada de futuras decisões frente ao melhoramento profissional ressignificando suas práticas. Nessa concepção, contamos com o pensamento de Cunha (1997, p. 2), ao afirmar que, "quando uma pessoa relata os fatos vividos por ela mesma, percebe-se que reconstrói a trajetória percorrida dando-lhe novos significados". Do mesmo modo, Nóvoa (1992), Finger e Nóvoa (2010), Ferrarotti (2010; 2014) e DeloryMomberger (2014) afirmam que as narrativas fornecem registros ricos que contribuem na ação investigativa e também na própria formação humana e profissional dos envolvidos.

Como já mencionado na introdução desse texto, na conjuntura do projeto colaborativo OBEDUC, desenvolvido pela parceria universidade-escola, em um município do estado de Mato Grosso, constatou-se a inclusão de LIC nos anos iniciais do EF, na 
matriz curricular da rede de ensino do município sendo recomendada no primeiro ciclo $\left(1^{\circ}\right.$, $2^{\circ}$ e $3^{\circ}$ ano) e obrigatória no segundo ( $4^{\circ}$ e $5^{\circ}$ ano). Aos coordenadores do projeto colaborativo foi solicitada uma formação específica para o trabalho de ensino de LIC, de modo a oferecer conhecimento para atender as necessidades formativas das professoras pedagogas, as quais não receberam instrução para tal na graduação.

No contexto das pesquisas de mestrado, uma concluída e socializada, e a outra em andamento, a solicitação foi contemplada com dois cursos de formação continuada com estudos para o ensino de LIC, com o total de 100 horas: o primeiro com carga horária de 20 horas, e o segundo com 80. Os conteúdos estudados nos encontros formativos foram escolhidos conforme a matriz curricular do município, e, para registro, optou-se por narrativas colhidas mediante entrevistas e diário de campo. As discussões fomentadas suscitaram reflexões a respeito das realidades de cada docente, suas práticas educativas e necessidades formativas para trabalhar com LIC. Os dados obtidos com as investigações revelaram que as partícipes buscam conhecimento em suas experiências enquanto discentes na Educação Básica, a partir do auxílio de colegas de trabalhos e filhos que estudavam em cursinhos de inglês e assim auxiliavam a mãe professora, livros didáticos e apostilas de suas próprias buscas, visto que tais materiais não são disponibilizados pela escola.

Para fins do presente texto, das duas ferramentas de coleta utilizadas, selecionamos as entrevistas semiestruturadas para análise, as quais foram balizadoras no intuito de captar e entender os reflexos da formação na profissionalidade das professoras que participaram das pesquisas. Segundo Lüdke e André (1986, p. 34), este gênero "permite a captação imediata e corrente da informação desejada, praticamente com qualquer tipo de informante sobre os mais variados tópicos".

Para esse texto, destacamos três excertos das entrevistas, os quais fazem referências às necessidades formativas de três professoras pedagogas no exercício de sua profissão como docentes de LIC. Elas são docentes em escolas de um município do estado de Mato Grosso, duas lecionam para o $4^{\circ}$ ano do EF e uma para o $5^{\circ}$. A escolha dos trechos deve-se ao fato de que os depoimentos descrevem de forma breve as realidades de cada profissional e apresentam traços de insegurança e angústia que merecem ser compartilhados. Com o intuito de preservar a identidade das partícipes das pesquisas, adotaremos codinomes para este fim, quais sejam Flordelis, Maria e Cinthia.

A pesquisa aqui proposta segue no viés dos projetos colaborativos, os quais, coadunando com Pereira (2017), objetivam maior reflexão dos professores envolvidos em 
relação ao trabalho didático/pedagógico e ao desencadear de ações educativas voltadas para a sala de aula.

$\mathrm{Na}$ sequência, apresentamos as análises dos dados obtidos por meio dos registros nos diários e as entrevistas com três professoras pedagogas do EF anos iniciais, as quais trazem, em seus relatos, necessidades formativas enquanto professoras de LI para crianças, além de reflexões sobre as práticas de ensino.

\section{Análise dos dados}

Considerando as reflexões propostas mediante à temática da formação, as quais apontam as fragilidades e necessidades formativas dos professores, trazemos aqui as análises de três excertos, os quais fazem referências às necessidades formativas de três professoras pedagogas no exercício de sua profissão como docentes de LIC. O fato é que as professoras não receberam formação em LI enquanto graduandas de Pedagogia, e aqui perceberemos os desdobramentos de seu exercer profissional e suas práticas. Esses aspectos são permeados por quadros de insegurança devido ao silenciamento nos currículos de licenciatura encrustado nos fazeres pedagógicos.

A professora do $5^{\circ}$ ano do EF, Flordelis, afirma que

[...] a gente trabalha com inglês em sala de aula, mas é complicado porque a gente sabe que não recebe muita formação, e hoje em dia nossas crianças são muito cheias de informações. As redes sociais, por exemplo, estão todo dia na vida deles, então, o mais importante é trabalhar principalmente com os conteúdos que estão na grade. Como as colegas falaram, a gente trabalha o conteúdo na escrita, e a pronúncia é outra, e às vezes, a gente pronuncia de uma forma e eles já dizem: 'não professora, não é assim, por que eu vi na internet', ou porque assistiram num joguinho de inglês, as informações estão para eles muito clara, e a gente se sente insegura porque não é o conteúdo que a gente domina, então assim, é frustrante porque eu espero uma coisa e na realidade, na aula é outra coisa que acontece. Meu filho faz um curso, ele gosta muito de inglês e esses dias eu estava 'explorando' ele, e ele me disse que eu deveria estudar inglês. Eu sinto muita dificuldade [...] (Entrevista Flordelis, 2019).

O desabafo de Flordelis é como um grito por socorro. Ela narra seus sentimentos, refletindo sobre suas práticas e vivências ao se deparar com a demanda do ensino da LI 
com suas crianças. Percebe-se que a professora é tirada do conforto, daquilo que lhe aparenta seguro e isso provoca sentimento de culpa, incapacidade, falta de preparo e conhecimento sobre o assunto.

Na perspectiva dos estudiosos do método (auto)biográfico, o ato de narrar pode propiciar ressignificações e transformações que são fundamentais para a formação do professor, conforme declara Cunha (1997, p. 187), assim como fez Flordelis, "quando uma pessoa relata os fatos vividos por ela mesma, percebe-se que reconstrói a trajetória percorrida dando-lhe novos significados", pois, "a narrativa não é a verdade lateral dos fatos mas, antes, é a representação que deles faz o sujeito e, dessa forma, pode ser transformadora da própria realidade”. Argumenta-se com essas declarações, o uso das narrativas no trabalho formativo com pessoas, principalmente ações fomentadas pelos agentes da educação.

No excerto da professora Flordelis, é nítida a angústia profissional frente ao ter que ensinar LI e lidar com seus alunos, muitas vezes, mais capacitados linguisticamente, quando muitas dúvidas e receios pairam ao longo do processo de lecionar um conteúdo, para o qual ela se sente insegura. Então, o quadro de crise do profissionalismo (TARDIF, 2017) se faz presente. Isto denota incapacidade em lidar com a língua por meio das palavras que sugerem impossibilidades tais como "complicado, insegura, frustrante e dificuldade". Assim, os reflexos das lacunas formativas deixados enquanto licencianda são os que mais refletem no cotidiano de seu agir pedagógico, ao relatar que é complicado trabalhar LI em sala de aula por não ter muita formação. Isso fica registrado por Maria e Cinthia, como veremos na sequência.

Ao problematizar a formação inicial e contínua, Gatti (2014, p. 47) afirma que "o professor é um profissional e que há necessidade de dotá-lo [...] de condições que lhe permitam atuar eficazmente em escolas e ser criativo em seu trabalho construindo sua autonomia profissional”. Para a autora, isto provém de uma formação adequada, oferecida tanto nas universidades, quanto nas secretarias municipais de ensino, por meio de formação contínua e assistência a esse professor em início de carreira. Nessa mesma perspectiva, está o projeto colaborativo OBEDUC, o qual trabalha com os professores no sentido de atender suas demandas profissionais. Nesse sentido, vale destacar a visão de Maria quanto à sua realidade nas práticas de ensino de LIC do $4^{\circ}$ ano do EF. 
[...] então, aqui no curso, ainda enrola a língua um pouco, porque eu não consigo mesmo falar, você fica lá, explica e fala alí, e a gente repete e fala, e aí você pede para fazer, falar as frases. Então é só naquele momento mesmo alí na sala de aula, na hora de preparar a aula de inglês, falar com eles. Eu treino aquelas palavras que eu vou falar na sala de aula, que eu vou estudar com eles, e quando eles perguntam alguma coisa, aí a gente tenta e o que eu não sei eu acabo levando pra casa para depois responder na próxima aula, mas estamos trabalhando assim, o básico mesmo. Então, pra mim, assim, eu estou tendo dificuldade sim para estar realizando essas aulas, para estar preparando as aulas para as crianças, mas estou me esforçando, fazendo o que posso fazer para estar auxiliando elas alí. E falo para elas: tudo de novo que vocês encontrarem, que vocês aprenderem a falar, anotem no caderninho de vocês, já vão trazendo, a gente preparou um caderninho só para inglês. [...] Aí que eu comecei a introduzir na sala de aula, e aí a gente escolhe a sexta-feira pra dar aula de inglês, porque é logo depois da quinta que a gente tem o encontro aqui, e aí na sexta também porque era um horário que dava para eu tirar umas aulas de português e colocar o inglês [...] (Entrevista Maria, 2017).

O relato de Maria apresenta uma reflexão sobre a prática acerca do quanto é difícil articular todas as demandas da prática docente, principalmente quando há falta de conhecimento de determinado assunto, mas, ao mesmo tempo, transmite um sentimento de esperança nas afirmações sobre a dedicação à profissão tendo em vista a aprendizagem dos alunos.

Professoras como Maria, Flordelis e Cinthia, segundo os estudos de Cardoso (2018, p. 118) "são profissionais que são estimuladas a agir, estudar e articular-se em prol de uma causa", pois se sentem “inquietas e provocadas por situações do cotidiano". Desse modo, são docentes que, conforme Nóvoa (1992), Imbernón (2009) e Gatti (2014), se debruçam sobre a profissão num estágio contínuo, que não se finaliza na graduação, e sim apenas começa.

Sobre isto, André (2016), ao discorrer sobre a evolução das perspectivas sobre formação docente, inicial e contínua, justifica que "a concepção que temos hoje é a de que a formação inicial é apenas uma fase de um processo de desenvolvimento profissional, que se prolonga ao longo de toda a vida profissional”. Todavia, segundo a autora, é preciso reconhecer que se dispor a trabalhar como docente significa

[...] entender que continuará seu processo de aprendizagem ao longo da vida, pois a docência exige estudo e aperfeiçoamento profissional para que possa responder às demandas da educação escolar inserida em uma realidade em constante mudança [...] (ANDRÉ, 2016, p. 30).

Revista Devir Educação, Lavras, vol.3, n.2, p.92-113 jul./dez., 2019. 
O engajamento das docentes em buscar sanar algumas angústias da profissão a partir dos estudos e a partipação em ações de formação contínua, conforme apontam os relatos, e ainda com as estratégias que desenvolvem ao longo da carreira para darem conta de tudo que é exigido dos professores, tal como discute Imbernón (2009), são movimentos cruciais para a profissão em questão, principalmente no contexto atual em que o conhecimento ultrapassa os limites das barreiras geográficas e é produzido em esferas digitais.

A professora Cinthia também expõe sua realidade, conforme o excerto abaixo.

[...] é complicado, eu ainda gosto, busco, mas eu vejo que tem professores que eles não conseguem, querendo ou não, não conseguem nem para eles quanto mais para passar para o aluno. E aí, é difícil, porque se a gente não incluir no nosso dia a dia, até nas outras disciplinas, sabe, chega ali, a memória, até para acostumar mesmo, e colocar algumas coisas na parede, na sala, que é o cotidiano né, rótulos, e trabalhar, não vai. Porque é uma aula só por semana, uma hora, é bem pouco, então assim, se o professor não buscar mesmo, não consegue. Eu penso assim, que o inglês deveria ser bem mais valorizado, e assim, ter um professor mesmo da área, pelo menos duas horas por semana. Porque a gente pensa que não, mas é o nosso dia a dia, é o cotidiano, e hoje você vê para a gente, tantas profissões que para quem tem a língua inglesa é tão mais fácil [...]. (Entrevista Cinthia, 2017).

Cinthia, ao ponderar sobre sua realidade, reflete sobre a inclusão da LI na matriz curricular dos anos iniciais e problematiza essa responsabilidade dada ao pedagogo. Observa-se um tom de desabafo em que há várias indagações que surgem para as quais não temos respostas imediatas, situações estas em que o melhor escape é encontrar formas de aprimorar a prática e minimizar as angústias da profissão.

Conforme as pesquisas apresentadas na obra de Nóvoa e Finger (2010) e os estudos apurados por Cardoso (2018, p. 116), atitudes como as de Flordelis, Maria e Cinthia, “de pronunciamento, confessando a angústia ou denunciando a realidade [...] representados a partir do exercício narrativo e reflexivo", alimentam a discussão e favorecem "a formação de si e do outro". Assim, a narrativa contribui no sentido da formação que envolve diferentes agentes envolvidos no processo educativo e também da própria autoformação. Conforme Cunha (1997, p. 188), o trabalho de registro e reflexão no ato narrativo "pode ser um processo profundamente emancipatório em que o sujeito aprende a produzir sua própria formação, autodeterminando a sua trajetória”. Nesse sentido, segundo revela André (2016), profissionais como Cinthia, Maria e Flordelis são do tipo que reconhecem os movimentos 
de mudança na educação e compreendem que a qualidade desta depende da dedicação delas nos estudos formativos da profissão.

Fica evidente na fala de Cinthia o quanto a falta de conhecimento da LI traz insegurança a ponto de afirmar que a função do ensino para as crianças deve restringir-se ao profissional especializado em LI. Desse modo, retomamos uma das indagações que norteiam o atual estudo: quem deve atuar no ensino e aprendizagem de LEC, o professor formado em Letras ou o professor formado em Pedagogia?

A mesma preocupação é suscitada por Celani (2010) quando ela analisa os dilemas dos cursos de licenciatura, principalmente os de dupla habilitação. A autora declara que

[...] o ensino de língua estrangeira na escola, particularmente na escola pública, está entregue a professores que não têm nem o domínio que poderíamos chamar de básico na língua estrangeira que supostamente deveriam ensinar. Além disso - o que também é grave, não foram expostos nem a um mínimo esperado em termos de familiaridade com um referencial teórico; não lhes foi proporcionada uma educação reflexiva sobre o ensinar, sobre o ensinar uma língua estrangeira e, particularmente sobre o ensinar uma língua estrangeira em situações adversas. A formação pré-serviço é inadequada e insuficiente. Talvez aí esteja a razão da crença generalizada de que 'língua estrangeira não se aprende na escola'. De fato, não se aprende, com professores despreparados. (CELANI, 2010, p. 61, grifo da autora).

Sobre o parecer da autora, Cardoso (2018, p. 125) argumenta que este problema e outros que surgem no processo "poderiam ser adequadamente manejados e solucionados se houvesse uma atenção maior por parte dos representantes governamentais em ofertar mais oportunidades de formação e estudos”, essencialmente, como é o caso desta pesquisa, "quando há a demanda para o ensino de conteúdos não conhecidos pelo profissional".

Defendemos e sugerimos que há a necessidade de professores formados em Pedagogia e professores formados em Letras Inglês se unirem para que, juntos, numa perspectiva de grupos colaborativos, possam "promover reflexões e com isso ressignificação de práticas a partir do convívio com dilemas, desafios e necessidades apresentadas pelos professores, junto às escolas", como asseveram Lima e Oliveira (2018, p. 4), a fim de diminuir os reflexos negativos da profissão professor e assim possam contribuir com uma educação de maior qualidade para nossas crianças, principalmente no que concerne aos estudos de LI.

Revista Devir Educação, Lavras, vol.3, n.2, p.92-113 jul./dez., 2019. 
Os trechos e análises aqui apresentadas suscitaram discussões e reflexões que são pertinentes para a atualidade, visto que a LI está dominando os diferentes meios de interação social e ainda é precário o olhar e atenção dado ao ensino e aprendizagem da língua, principalmente nas práticas educativas com crianças.

\section{Considerações}

As reflexões neste artigo visam refletir e problematizar a atual realidade do ensino de LI para crianças no Brasil, uma vez que as pesquisas evidenciam discussões a respeito de um olhar mais incisivo para os silenciamentos tanto nos currículos, quanto nas políticas públicas educacionais em relação ao ensino e aprendizagem de LI, bem como na formação de pedagogos, a qual necessita de uma atenção especial.

Partindo do objetivo, deparamo-nos com conjunturas educacionais em que professores, apresentando diversas necessidades formativas em relação à LIC, entram em sala de aula para desenvolver sua profissionalidade e, ao término de sua aula, percebe o quanto tem sido desafiador ensinar algo para o qual não obteve devida formação, gerando nos docentes quadros de insatisfações, inseguranças e possível desistência da profissão.

Tendo em vista que vários autores têm se debruçado em investigar o panorama educacional de LIC supracitado, sabemos que os reflexos de mudanças ainda podem ser mais expressivos. Após dialogarmos com esses autores e suas pesquisas, investigarmos essa mesma temática, percebemos que professores, formados tanto em Pedagogia como em Letras LI, apresentam silenciamentos em sua fomação, no que tange à competência linguística e ao saber lidar com o ensino de LI para crianças.

Após análises de dados, sugerimos que o trabalho colaborativo pode se mostrar uma ferramenta de compartilhamento de situações diversas, positivas ou negativas, e delas suscitarem possibilidades de articular e potencializar saberes entre seus pares, e, consequentemente, promover um ensino eficaz e significativo para as referidas crianças.

Urge a reestruturação dos currículos da formação inicial e de políticas públicas de formação continuada aos docentes dos anos iniciais.

\section{Referências}

Revista Devir Educação, Lavras, vol.3, n.2, p.92-113 jul./dez., 2019. 
ANDRÉ, M. (Org.). Práticas inovadoras na formação de professores. Campinas: Papirus, 2016.

AGRA, C. B.; IFA, S. A introdução da língua inglesa no EFI público à luz dos multiletramentos: Possibilidades e reflexões. In: ROCHA, C. H.; TONELLI, R. A.; SILVA, K. A. (Org.). Língua estrangeira para crianças: Ensino - aprendizagem e formação docente. Campinas, São Paulo: Pontes Editores, 2010, p. 63-93.

BOGDAN, R.; BIKLEN, S. Investigação qualitativa em educação: uma introdução à teoria e aos métodos. Porto, Portugal: Porto Editora LDA, 1994.

BRASIL. Parâmetros Curriculares Nacionais: terceiro e quarto ciclo do Ensino Fundamental: língua estrangeira. Secretaria de Educação Fundamental, Brasília, 1998.

BRASIL. Lei de Diretrizes e Bases da Educação Nacional, de 06 de fevereiro de 2006. Diário Oficial da União, Brasília, 2006. Disponível em: <https://www2.senado.leg.br/bdsf/bitstream/handle/id/70320/65.pdf>. Acesso em: 10 jul. 2019.

BRASIL. Diretrizes Curriculares Nacionais Gerais da Educação Básica. Ministério da Educação, Brasília, 2013. Disponível em: <http://portal.mec.gov.br/index.php?option=com_docman\&view=download\&alias=15548-dc-n-educacao-basica-nova-pdf\&Itemid=30192>. Acesso em: 16 jul. 2019.

BRASIL. Ministério da Educação. Base Nacional Comum Curricular. Brasília, 2017. Disponível em: <http://basenacionalcomum.mec.gov.br/a-base/>. Acesso em: 10 ago. 2019.

CARDOSO, F. M. Professoras Iniciantes e as Práticas de Língua Inglesa no Cotidiano da Profissão. 2018. 152 f. Dissertação (Mestrado em Educação) - Universidade Federal de Mato Grosso, Rondonópolis, 2018.2 Disponível em: <https://www1.ufmt.br/ufmt/unidade/userfiles/publicacoes/f7788f5bce90ecfadf6267cac97269 0c.pdf $>$. Acesso em: 15 ago. 2019.

CELANI, M. A. A. Formação de Professores de Línguas: rumos para uma sociedade crítica e sustentável. In: GIMENEZ, Telma; MONTEIRO, Maria Cristina de Góes (Org.). Formação de professores de línguas na América Latina e transformação social. Campinas: Pontes Editores, 2010, 2 p. 57-67. 20 Disponível <http://pos.letras.ufg.br/up/26/o/formacao_professores.pdf>. Acesso em: 18 set. 2017.

CUNHA, M. I. Conta-me agora! As narrativas como alternativas pedagógicas na pesquisa e no ensino. Revista da Faculdade de Educação, São Paulo, v. 23, n. 1-2, p. 185-195, jan./dez. 1997. Disponível em: <http://www.revistas.usp.br/rfe/article/view/59596/62695>. Acesso em: 19 jul. 2019.

DELORY-MOMBERGER, C. As Histórias de Vida: da invenção de si ao projeto de formação. Tradução: Albino Pozzer. Natal: EDUFRN; Porto Alegre: EDIPUCRS; Brasília: EDUNEB, 2014. 
DOMINICÉ, P. O processo de formação e alguns dos seus componentes relacionais. In: FINGER, Matthias; NÓVOA, António. O método (auto)biográfico e a formação. Natal: EDUFRN; São Paulo: Paulus, 2010, p. 83-95.

DOMINICÉ, P. Prefácio à Edição Francesa. In: DELORY-MOMBERGER, Christine. Biografia e Educação: Figuras do indivíduo-projeto. Tradução: Maria da Conceição Passeggi, João Gomes da Silva Neto, Luis Passeggi. 2. ed. Natal: EDUFRN, 2014, p. 21-31.

FERRAROTTI, F. Sobre a autonomia do método biográfico. In: FERRAROTTI, F (Org.); NÓVOA, António; FINGER, Mathias. O método (auto)biográfico e a formação. Natal: EDUFRN; São Paulo: Paulus, 2010, p. 31-58.

FERRAROTTI, F. História e história de vida. Tradução: Carlos Eduardo Galvão, Maria da Conceição Passeggi. Natal: EDUFRN, 2014.

FREIRE, P. Pedagogia da Autonomia: saberes necessários à prática educativa. São Paulo: Paz e Terra, 1997.

GHEDIN, E.; FRANCO, M. A. S. Questões do método na construção da pesquisa em educação. 2. ed. São Paulo: Cortez, 2011.

IMBERNÓN, F. Formação permanente do professorado: novas tendências. Tradução: Sandra Trabucco Valenzuela. São Paulo: Cortez, 2009.

LIMA, A. M. C; OLIVEIRA, A. C. As práticas reflexivas de professoras iniciantes com formação em grupos de pesquisa colaborativos. In: XIV ENCONTRO DE PESQUISA EM EDUCAÇÃO DA REGIÃO CENTRO OESTE - AMPED, 2018, Cáceres, Anais... Cáceres: Editora, 2018.

LIMA, A. P. de; MARGONARI, D. M. A prática de ensino e a formação de professores de inglês para crianças. In: ROCHA, C. H.; TONELLI, R. A.; SILVA, K. A. (Org.). Língua estrangeira para crianças: Ensino - aprendizagem e formação docente. Campinas: Pontes Editores, 2010, p. 187-202.

LÜDKE, M.; ANDRÉ, M. E. D. Pesquisa em Educação: abordagens qualitativas. São Paulo: UPU, 1986.

NÓVOA, A. Os professores e a sua formação. Lisboa: Porto, 1992.

NÓVOA, A.; FINGER, M. O método (auto)biográfico e a formação. Natal: EDUFRN, São Paulo: Paulus, 2010.

PAIVA, V. L. M. O. A LDB e a legislação vigente sobre o ensino e a formação de professor de língua inglesa. In: STEVENS, C. M. T; CUNHA, M. J. Caminhos e colheitas: ensino e pesquisa na área de inglês no Brasil. Brasília: UnB, 2003, p. 53-84. Disponível em: <http://www.veramenezes.com/ensino.htm>. Acesso em: 10 jun. 2019. 
PASSOS. L. F. Práticas formativas em grupos colaborativos: das ações compartilhadas à construção de novas profissionalidades. In: ANDRÉ, Marli (Org.). Práticas inovadoras na formação de professores. Campinas: Papirus, 2016, p. 165-188.

PEREIRA, P. S.Os movimentos reflexivos presentes nas pesquisas do núcleo UFMS no projeto em rede observatório da educação. Revista Formação Docente, Belo Horizonte, v. 9, n. 16, p. 95-108. jan./jun. 2017.

RAJAGOPALAN, K. Prefácio A língua Estrangeira para crianças: um tema no mínimo ambíguo. In: ROCHA, C. H.; TONELLI, J. R. A.; SILVA, K. A. (Org.). Língua Estrangeira para Crianças: ensino-aprendizagem e formação docente. Campinas: Pontes Editores, 2010, p. $9-12$.

RICHARDS, J. C. Growing Up with TESOL. English Teaching Forum, New York, v. 46, n. 1, p. 2-11, janeiro. 2008.

ROCHA, C. H.; TONELLI, R. A.; SILVA, K. A. (Org.). Língua estrangeira para crianças: Ensino - aprendizagem e formação docente. Campinas: Pontes Editores, 2010.

ROCHA, C.; LIBERALI, F. C. Ensino de línguas nos anos iniciais de escolarização: reflexões sobre bilinguismo e letramentos. In: RODRIGUES, André Figueiredo; FORTUNATO, Marina Pinheiro (Org.). Alfabetização e letramento: prática reflexiva no processo educativo. São Paulo: Humanitas, 2017, p. 127-144.

SILVA, A. P. da. Professores Iniciantes Egressos do Curso de Pedagogia e o Abandono da Carreira Docente no Município de Rondonópolis/MT. 2018. 110 f. Dissertação (Mestrado em Educação) - Universidade Federal de Mato Grosso, Rondonópolis, 2018. Disponível em:

<https://www1.ufmt.br/ufmt/unidade/userfiles/publicacoes/ef97cfb2fdd9fac7e163fe1cabbd1b 75.pdf>. Acesso em: 15 ago. 2019.

SZUNDY, P. T. C. Prefácio. In: TONELLI, J. R. A.; PÁDUA, L. S., OLIVEIRA, T. R. R. (Org.). Ensino e formação de professores de línguas estrangeiras para crianças no Brasil. Curitiba: Appris, 2017, p. 11-13.

TARDIF, M. Saberes docentes e formação profissional. Petrópolis: Vozes, 2017.

TONELLI, J. R. A.; PÁDUA, L. S.; OLIVEIRA, R. R. O. (Org.). Ensino e formação de línguas estrangeiras para crianças no Brasil. Curitiba: Appris, 2017. 